\title{
Structural complexity analysis for industrial ecosystems: A case study on LuBei industrial ecosystem in China
}

\author{
Liang Chen ${ }^{\mathrm{a}, \mathrm{b}, *}$, Rusong Wang ${ }^{\mathrm{a}}$, Jianxin Yang ${ }^{\mathrm{a}}$, Yongliang Shi ${ }^{\mathrm{a}}$

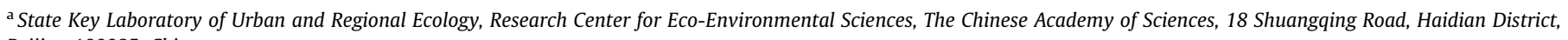 \\ Beijing 100085, China \\ b China National Institute of Standardization, 4 Zhichun Road, Haidian District, Beijing 100088, China
}

\section{A R T I C L E I N F O}

\section{Article history:}

Received 22 January 2009

Received in revised form 21 October 2009

Accepted 21 October 2009

Available online 17 November 2009

\section{Keywords:}

Ecological complexity

Industrial ecosystem

Natural ecosystem

Structural analysis

Structure complexity

Industrial species

\begin{abstract}
A B S T R A C T
Natural ecosystems and human societies have evolved in many diverse ways and they are both complex systems. Our learning from the structure complexity of natural ecosystems can help us to redesign the structure of industrial system. Thus the materials and energy efficiency of industrial systems can be improved well to achieve the sustainable goals. In this paper, Structural Analysis Method for Industrial Ecosystems (SAMIE) is introduced and applied in the analysis of the structure complexity and efficiency of the industrial ecosystems. The industrial ecosystem is analyzed based on the industrial species' classification, which is analogous to the natural ecosystem. A set of indicators are developed to evaluate the industrial system, in order to explore the problems of structural complexity, identify the limiting factors of industrial ecosystem evolution, and strengthen the capacity of adaptation and selforganization. A case study on LuBei industrial ecosystem in China has been selected to apply the SAMIE approach.
\end{abstract}

(c) 2009 Elsevier B.V. All rights reserved.

\section{Introduction}

Since the Brundtland Report of 1987, there have been many reflections on the issues of sustainability and the future of human development (Yang and Lay, 2004). To avoid a "feel good" sustainable approach, how can we make the concept of sustainability more operational and manageable? What kind of planning tools are needed so that we can provide solutions rather than the old sustainability cliche (Harper and Graedel, 2004)? From 1980s, one emerging ecological planning approach, industrial ecology, is applied here as a way to plan industrial areas (Graedel and Allenby, 1995; Cohen-Rosenthal, 2004). It goes beyond the traditional "end of pipe" idea of pollution control, and tries to foster "thinking like an ecosystem" (Cote and Cohen-Rosenthal, 1998).

Actually the ecological complexity indicates the degree to which ecological systems comprising biological, social and physical components incorporate spatially explicit heterogeneity, organizational connectivity or structure, and historical contingency through time. These three dimensions of biocomplexity heterogeneity, connectivity, and history - will be explored as axes of increasing complexity (Cadenasso et al., 2006).

\footnotetext{
* Corresponding author. Fax: +86 1058811714.

E-mail address: ecochenliang@yahoo.com.cn (L. Chen).
}

Moreover natural communities of living organisms are complex systems with their internal structure, inherent entirety and organization (Azovsky and Andrey, 2009). Organized complexity is one key aspect of ecological complexity. It's a characteristic feature of ecological systems with heterogeneous components interacting at several spatial-temporal scales. The hierarchy theory is a powerful epistemological framework to describe such systems by decomposing them vertically into levels and horizontally into holons. It was at first developed in a temporal and functional perspective and then, in the context of landscape ecology, extended to a spatial and structural approach (Ratze et al., 2007).

In fact, natural systems and industrial systems are both complex systems in themselves, but because of the shift from nature to predominantly human-dominated drivers, many of those problems involve the additional complexity of interactions between natural and industrial systems. Understanding must come from the examination of which linkages exist between these two systems, and not from the examination of those systems themselves in isolation ( $\mathrm{Li}, 2004)$.

Complex systems thinking and approaches could provide us a new opportunity to comprehensively understand the nature of industrial ecosystems, which allow the development of management strategies for sustainability that are adaptable and flexible, able to deal with uncertainty and surprise, and have the capacity to adapt to change. Just as a mature natural ecosystem, a classic and 
complex structure can be developed in industrial system to fulfill its function and improve the production efficiency.

In most industrial systems today, the speed of composition and decomposition of products is not as balanced as in natural systems (Ulgiati and Brown, 1998). Therefore, structural analysis of industrial ecosystems is of key importance in the study of industrial ecology. The principle components of structural analysis observed are, calculating flux rates between producers, consumers and recyclers, as well as controlling limiting factors that restrict the evolution of an industrial ecosystem (Korhonen, 2002).

Nowadays, many analysis tools are currently used by industrial ecologists, such as MFA, IOA, LCA and so on. They are reviewed as below.

\subsection{Mass balance and material flow accounting}

Mass-balance analysis is an important tool in all kinds of investigations where it is important to follow material fluxes (Finnveden and Moberg, 2005). The bulk internal flow material flow analysis (MFA) models developed as material flow balance models that focused on both material inputs and output flows and stock accumulations, induced by the entire societal metabolism of a given system. An essential principle is that of "materials balance" in order to derive consistent and balanced measures of material inputs and outputs across the economy-environment system boundary. The approach has also incorporated the identification and quantification of physical flows of "bulk" material categories within at least a limited number of subsystem components of the economic region under study. The MFA approach aims to reveal the fundamental nature of system sources of flows and provides an overview of the structural nature of the material basis of economies (Daniels and Moore, 2002).

It holds for both conservative substances and material that is converted in the process. Mass balances are the fundamental basis for calculations of the flow of mass through an open system (Guinee et al., 1999; Adriaansee et al., 1997). A mass balance equation can be expressed in several ways. It can be written with input on the left side equating to output on the right or with all elements on the left equating to zero on the right (Gleser, 1997).

MFA is a family of different methods (Bringezu et al., 1997). Different MFA methods have different objects in focus. Three types are briefly mentioned here: Total Material Requirement (TMR), Material Intensity per Unit Service (MIPS) and Substance Flow Analysis (SFA). TMR and MIPS can also be described as bulk-MFA methods (Matthews et al., 2000; Bringezu, 2000; Spangenberg et al., 1999; Adriaansee et al., 1997).

In principle, MFA methods can be used in both descriptive and change-orientated studies. In practice, the bulk-MFA methods (TMR and MIPS) have typically been applied in accounting studies using accounting methodology and data.

Good examples of mass balances include Ayres (1989) on heavy metals in river basins; Frosch and Gallopoulos (1989) on PVC plastic, iron, and platinum in the U.S. economy; Ayres et al. (1994) on global carbon and nitrogen; and Thomas and Spiro (1994) on global lead and cadmium.

\subsection{Input-output analysis}

The input-output analysis (IOA) (Miller and Blair, 1985) has been improved by many researchers in different fields for the sake of the conflicts between economic and environment.

Physical input-output tables (PIOT) allow national-level analysis that extends upon conventional input-output methodology and classifications to incorporate environmental resource and waste output "sectors" to provide measures of the physical flow of materials and goods within the economic system and between the economic system and the natural environment. This approach involves the exhaustive physical coverage of the movement (origins and uses) of most environmentally relevant materials induced by an economic region. The PIOT method traces how natural resources enter, are processed, and subsequently as commodities, are moved around the economy, used, and finally returned to the natural environment in the form of residuals. It undertakes the detailed investigation of intersectoral physical flows of environmental resources inputs and commodity weights and residuals, and given this intersectoral specification and transactions matrix structure, has the ability to evaluate the cumulative environmental burden (total direct and indirect effect material requirements and pressures) of private consumption and other final demand for the products of different industries (Pederson, 1998; Stahmer et al., 1997).

And in recent years, IOA has been applied in the industrial ecosystems, especially to assess the environmental effects of the production and utilization phases of products.

The input-output matrixes were used for describing trade between industries. Traditionally, it was expressed by the monetary values. An IOA can be applied to include environmental impacts either by adding emissions coefficients to the monetary input-output tables or by replacing the monetary input-output matrixes with matrixes based on physical flows (Joshi, 2000; Lave et al., 1995). The results from such environmental IOA can be presented for industrial sectors as well for industrial groups. The IOA was typically applied using descriptive data and methodology for accounting purposes. A recent exception is, however, the approach to a dynamic environmental life-cycle assessment based on input-output modeling (Joshi, 2000).

\subsection{Life-cycle assessment}

Life-cycle assessment (LCA) is an environmental management tool for identifying (and comparing) the whole life cycle, or cradleto-grave, environmental impacts of the creation, marketing, transport and distribution, operation, and disposal of specific human artifacts (Vigon et al., 1993). An ISO standard has been developed for LCA that provides a framework, terminology and some methodological choices (ISO, 1999, 1998, 1997). The approach is intrinsically holistic in nature and considers direct and, ideally, related processes and hidden, nonmarket flows of raw materials and intermediate inputs, and waste and other material and energy outputs associated with the entire existence or "product chain" or "system". The LCA procedure often involves a comparison of a small number of substitutable products assumed to provide a similar consumption service. Initiatives have also been taken to develop best available practice of LCA application (Udo de Haes et al., 2002, 1999). As an analytical tool, LCA can be used both as a descriptive tool and a change-orientated tool with different choices of data and methodology.

\subsection{Industrial metabolism}

The concept of industrial metabolism was launched by Ayres in 1988 (Ayres and Simonis, 1994; Baccini and Brunner, 1991). He views the "metabolism of industry" as "the whole integrated collection of physical processes that convert raw materials and energy, plus labor, into finished products and wastes..." (Anderberg, 1998; Ayres and Simonis, 1994). The aim of industrial metabolism studies is to gain improved knowledge and to understand the societal uses of natural resources and their total impacts on the environment. The basic idea of industrial metabolism is to analyze the entire flow of materials, identify all possible emission sources and assess the effects associated with these flows. 


\subsection{Emergy analysis}

Emergy, specifically Solar Emergy, is "the available solar energy used up directly and indirectly to make a service or product" (Odum, 1996, 1994, 1988). Emergy analysis considers all systems as the networks of energy flow and determines the emergy value of the streams and systems involved. Emergy analysis presents an energetic basis for quantification or valuation of ecosystems' goods and services. Before, valuation methods in environmental and ecological economics estimate the value of ecosystem inputs in terms that have been defined narrowly and anthropocentrically. However emergy analysis tries to capture the ecocentric value. It attempts to assign the "correct" value to products and services based on a theory of energy flow in systems ecology. A fundamental principle of emergy analysis is the Maximum Empower Principle. It states that "systems that will prevail in competition with others, develop the most useful work with inflowing emergy sources by reinforcing productive processes and overcoming limitations through system organization" (Brown and Herendeen, 1996).

Above summarizes the main systemic analysis tools in the fields of ecological economy science and industrial ecology. However, all these macro-level analysis for collective decisionmaking has limits. Alone, mass balances do not provide a basis for prioritizing environmental problems or for evaluating proposed solutions. Decision makers need to link dissipative uses of materials with specific risks to public health, ecosystem viability, or quality of life (Graedel, 1994; Thomas and Spiro, 1994). Also, loop closing is an energy intensive task, so there may be trade-offs between energy efficiency and retention of materials in the system (O'Rourke et al., 1996). Further, tracking thousands of materials through a system is a challenging administrative task whose benefits and costs may not balance. Theses macro-level analysis of materials and energy flows tell us little about how to improve the efficiency of the industrial ecosystem; this typically requires information about how we meet technical challenges and make collective decisions.

Although industrial ecologists offer structural explanations for waste using the life-cycle framework, this type of structural analysis of the industrial ecological community may fail to reveal all of the ways to improve its aggregate performance. Descent to another level of detail is sometimes necessary. Further disaggregating must precede efforts to explain why different actors are responsible for different life-cycle stages, what the origins of existing industrial structure are, and how structural relationships might change.

Many industrial ecologists, with roots in the sciences, see their roles as providing "what?" guidance, as in "what problems should people worry about?" I argue that the field should be equally concerned with "how?" guidance, as in "how can people solve their problems?" Making the problem solvers visible is a logical first step in implementing the industrial ecology vision (Andrews, 2001). Industrial ecology encourages a focus on removing barriers to entrepreneurial activity. The natural tendency of a selforganizing system made up of self-interested individuals is to adapt and expand into every attractive niche (Ulanowicz and Robert, 2004).

So in this paper, on the base of the concept of biodiversity and the comparison between natural ecosystems and industrial ecosystems, a new structure analysis method named Structural Analysis Methods for Industrial Ecosystems (SAMIE) is introduced. The focus of SAMIE is to provide the analysis of an industrial ecosystem by assessing the structure and structural properties of the system as a whole to reveal all of the ways to improve its aggregate performance and to strengthen the capacity of adaptation and self-organization for industrial ecosystems. A case study on LuBei industrial system demonstrates the application of SAMIE.

\section{Structural Analysis Methods for Industrial Ecosystems (SAMIE)}

\subsection{The theoretical basis of SAMIE}

In fact, there are many close relationships between industrial ecosystems and nature. For example, the virgin materials of industrial ecosystems come from natural world. The wastes from industrial ecosystem leak into the natural world. So there are 3 inherent issues possessed by every industrial ecosystem: exhaustion, stagnancy, and the final products.

In the resource exploitation, when the output from a system is much higher than the input into it, which is far away from the minimum cost for restoring its damaged function, an ecological exhaustion will happen.

Conversely, when the input of a system far exceeds its output, resulting in an excessive quantity of materials and energy leaking into the environment, an ecological stagnancy will happen.

The ultimate goals of an ideal ecological industry are to minimize the ecological exhaustion and stagnancy, as the same time, to maximize the quantity and optimize the quality of final products.

The exhaustion, stagnation, and final products of an industrial system are based on the input and output of the industrial species within the whole system. Traditionally, the species in natural ecosystems can be divided into 3 levels according to the function of the species and the structure of the natural ecosystems: Autotrophs, Heterotrophs and Decomposers. And in natural ecosystem, the food and energy can be transmitted by the food chains among different component species. Similar to natural ecosystems, according to the function and the position in industrial ecosystem the materials in industrial ecosystem (industrial species) include 3 parts: raw materials, the medium product or waste, and the final product. In this research, these 3 parts can be categorized into Basal species, Intermediate species and Top species respectively (The Basal species referring to the raw materials, the Intermediate species referring to the medium product and waste, and the Top species referring to the final product in the industrial ecosystem). And all these materials can be transferred by the production chains (webs) in industrial ecosystems (Table 1 ).

The above is the fundamental concept of SAMIE. Based on this new view, the mathematical models of SAMIE can be developed to depict the vitality and structure of industrial ecosystems. SAMIE can also represent the strengths and weaknesses of the industrial species.

\subsection{Definition of the industrial species}

Industrial species is defined as all the materials participating in chemical reactions in one industrial ecosystem (the materials only participating in physical reactions are not included). According to the position and function in the industrial production chains, industrial species can be divided into basal species, intermediate species and top species. Basal species are the virgin materials for production from nature, which may supply the basic and important nutrition source for the industrial system. Intermediate species are those products processed from raw materials that would be processed into final products. Top species are those products processed from basal and intermediate species that cannot be further processed into other products and are sold (top species return the nutrition to industrial systems or society). 
Table 1

The composition of natural ecosystems and industrial ecosystems.

\begin{tabular}{|c|c|c|}
\hline Ecosystem & The composition of systems & Materials and energy flow \\
\hline Natural ecosystems & $\begin{array}{l}\text { Autotrophs (Krebs, 2001): Autotrophs pick up energy from the sun and materials } \\
\text { from nonliving sources. They are essential in ecosystems as they are the main } \\
\text { contributors of the net energy in a particular system. Green plants are the } \\
\text { typical autotrophs } \\
\text { Heterotrophs (Krebs, 2001): Heterotrophs pick up energy and materials by } \\
\text { eating living matter. They cannot synthesize their own food, and therefore } \\
\text { rely on other food sources found within the environment. Herbivores are } \\
\text { heterotrophs that live by eating } \\
\text { plants, and carnivores are heterotrophs that live by eating other heterotrophs } \\
\text { Decomposers (Krebs, 2001): Decomposers utilize energy from wastes } \\
\text { dead organisms, so complete the cycle by returning nutrients to the soil } \\
\text { or water, and carbon dioxide to the air and water. Decomposers may } \\
\text { consist of bacteria, fungi and soil animals }\end{array}$ & Food chains \\
\hline Industrial ecosystems & $\begin{array}{l}\text { The virgin materials (Basal species): The virgin materials for } \\
\text { production from nature } \\
\text { The medium product and waste (Intermediate species): The species } \\
\text { are processed from basal species and applied to process into } \\
\text { top species (the surplus of intermediate species can also be } \\
\text { sold, of course the waste are included) } \\
\text { The final product (Top species): The species are processed } \\
\text { from basal species and intermediate species that would } \\
\text { not be processed into other products and will be sold }\end{array}$ & Production chains \\
\hline
\end{tabular}

\subsection{The SAMIE approach}

In Ecology, there is a very important definition of food chain (Krebs, 2001) that is defined as a group of organisms interrelated by the fact that each member of the group feeds upon on the one below it and is in turn eaten by the organism above it in the chain. So by the food chains in the natural ecosystem, the eco efficiency of the nutrition transition in different hierarchy and the structure attributes of the system can be worked out. As the same, the industrial ecosystem can also be assessed by eco efficiency of the materials transition in different species hierarchy and the structure attributes.

By SAMIE, an industrial ecosystem can be modeled according to two valuation indices, i.e., Species Index and Rigidity.

\subsubsection{The indicators system of SAMIE}

The indicators system of SAMIE is described in the Table 2 . The indicators are classified into 3 levels. The primary indicators include Species Index and Rigidity; the secondary indicators include Intermediate-Basal Species Index (IBSI), Intermediate-Top
Species Index (ITSI), absolute rigidity, relative rigidity, and system rigidity; the tertiary indicators include input rigidity, output rigidity, and source relative rigidity.

\subsubsection{The Species Index}

2.3.2.1. Intermediate-Basal Species Index (IBSI). IBSI is defined as the ratio of mass between all intermediate species and basal species. The significance of IBSI is to measure the efficiency of raw material utilization. That is,

$\mathrm{IBSI}=\frac{\sum_{i=1} \mathrm{MI}_{i}}{\sum_{i=1} \mathrm{MB}_{i}}$

where $\sum_{i=1} \mathrm{MI}_{i}$ is total mass of the intermediate species, and $\sum_{i=1} \mathrm{MB}_{i}$ is total mass of the basal species. The value of IBSI indicates the proportion of basal species transforming into intermediate species. A higher value represents a larger proportion of basal species transforming into intermediate species.

Table 2

The indicators system of SAMIE.

\begin{tabular}{|c|c|c|c|}
\hline \multicolumn{4}{|l|}{ SAMIE } \\
\hline Primary indicators & Secondary indicators & Tertiary indicators & Description \\
\hline Species Index & $\begin{array}{l}\text { Intermediate-Basal Species } \\
\text { Index (IBSI) } \\
\text { Intermediate-Top Species } \\
\text { Index (ITSI) }\end{array}$ & & $\begin{array}{l}\text { The value of IBSI indicates the proportion of basal species } \\
\text { transformed into intermediate species } \\
\text { The value of ITSI indicates the proportion of intermediate } \\
\text { species transformed into top species }\end{array}$ \\
\hline \multirow[t]{3}{*}{ Rigidity } & Absolute rigidity & Input rigidity & $\begin{array}{l}\text { Absolute rigidity of one industrial species represents the } \\
\text { instability level of its own yield. Input rigidity indicates } \\
\text { the instability level of one species engaged in the input } \\
\text { process, while output rigidity assesses the instability } \\
\text { levels of species engaged in the output process }\end{array}$ \\
\hline & & Output rigidity & \\
\hline & System rigidity & $\begin{array}{l}\text { Source relative } \\
\text { rigidity }\end{array}$ & $\begin{array}{l}\text { Relative rigidity is defined as the total contribution of one } \\
\text { industrial species to the instability of all other species' } \\
\text { yields within that industrial ecosystem. Source relative } \\
\text { rigidity is the contribution of one species to the instability of } \\
\text { one other species' yield within that industrial ecosystem } \\
\text { System rigidity is used to assess the contributions of one } \\
\text { industrial species to the stability of entire industrial ecosystem }\end{array}$ \\
\hline
\end{tabular}


2.3.2.2. Intermediate-Top Species Index (ITSI). ITSI is defined as the ratio of mass between all intermediate species and top species. The significance of ITSI is to measure the efficiency of wastes recycling. That is,

$$
\mathrm{ITSI}=\frac{\sum_{i=1} \mathrm{MT}_{i}}{\sum_{i=1} \mathrm{MI}_{i}}
$$

where $\sum_{i=1} \mathrm{MI}_{i}$ is total mass of the intermediate species, and $\sum_{i=1} \mathrm{MT}_{i}$ is total mass of the top species. The value of ITSI indicates the proportion of intermediate species transforming into top species. A higher value represents a larger proportion of Intermediate species transforming into top species. Likewise, this means that less waste is generated from the production.

2.3.2.3. Rigidity. The rigidity of one industrial species represents the instability level of its own yield, its contribution to the instability of other species' yield in an industrial ecosystem, and its contribution to the instability of the whole industrial ecosystem. So in this paper, the rigidity analysis will be divided into absolute rigidity, relative rigidity and system rigidity. Due to the significance of the intermediate species in an industrial ecosystem, the focus of rigidity analysis will be applied to the intermediate species.

2.3.2.4. Absolute rigidity. The absolute rigidity of one industrial species represents the instability level of its own yield. It can be got from the input rigidity and output rigidity.

(1) Input rigidity and output rigidity: Input rigidity is a measurement that indicates the instability level of one species in the input process. Output rigidity measures the instability level in the output process. Based on the mass flow of input and output in the production chains, and reference to Simpson Diversity Index (Onaindia et al., 2004; Simpson, 1949), the input and output rigidity can be calculated. That is,

$D^{\prime}=\frac{N(N-1)}{\sum_{i=1}\left(n_{i}-1\right) n_{i}}$

where $D^{\prime}$ is the Simpson Diversity Index, $N$ is total volume of input (output), $n_{i}$ is the volume of input (output) of type $i$ species.

(2) Absolute rigidity: Assuming the stable level of input and output flow of every species is identical, then, according to input and output rigidity, the absolute rigidity of species can be calculated as below.

$G=D_{\text {in }}^{\prime} \times D_{\text {out }}^{\prime}$

where $G$ is absolute rigidity of species, $D_{\text {in }}^{\prime}$ is input rigidity, $D_{\text {out }}^{\prime}$ is output rigidity.

The higher absolute rigidity of species indicates the larger variation of input and output of its own.

2.3.2.5. Relative rigidity. The relative rigidity is defined as the total contribution of one industrial species to the instability of all other species' yield in an industrial ecosystem. It can be got from source relative rigidity.

(1) Source relative rigidity: Source relative rigidity is one species' contribution to the instability of one other species' yield. In an industrial ecosystem, there are direct and indirect relationships between raw materials and products. Direct relationships can be further divided into 4 kinds. Exemplified by the relationships between $A$ and $B$, the first relationship is $A$ transforming into $B$ $(A \rightarrow B)$. The second relationship is $A$ and $B$ transforming into other materials $(A+B \rightarrow C)$. The third relationship is other materials transforming into $A$ and $B(C \rightarrow A+B)$. And the last relationship is $A$ transforming into $B$ as well as $B$ transforming into $A(A \leftrightarrow B)$. Here
$K A B$ is defined as the source relative rigidity of $A$ to $B$, and KBA is defined as the source relative rigidity of $B$ to $A$.

(i) For the first relationship, $A \rightarrow B$ : $K A B=B A_{i n}$, where $B A_{i n}$ is the percentage of $B$ transformed form $A$. $K B A=A B_{\text {out }}$, where $A B_{\text {out }}$ is the percentage of $A$ transforming into $B$.

(ii) For the second relationship, $A+B \rightarrow C$ : $K A B=B C_{\text {out }}$, where $B C_{\text {out }}$ is the percentage of $B$ transforming into $C$. $K B A=A C_{\text {out }}$, where $A C_{\text {out }}$ is the percentage of $A$ transforming into $C$.

(iii) For the third relationship, $C \rightarrow A+B: K A B=B C_{i n}, K B A=A C_{i n}$, where $B C_{i n}$ is the percentage of $B$ transformed from $C$. And $A C_{i n}$ is the percentage of $A$ transformed form $C$.

(iv) If the three chemical reactions mentioned above occurred simultaneously between $A$ and $B$, the relationship between them should be defined by which reaction is the dominant. In addition, the source rigidity of one species to its own is valued at 1 , such as $\mathrm{KAA}=1, \mathrm{KBB}=1$.

(v) For the last relationship, $A \leftrightarrow B$ : when $K A B$ is calculated, the relationship between $A$ and $B$ should be considered as $A \rightarrow B$. Likewise, when KBA is calculated, the relationship between $A$ and $\mathrm{B}$ should be considered as $\mathrm{B} \rightarrow \mathrm{A}$.

If there is no direct relationship between A and B, the source relative rigidity could be assessed by the agency material $C$ that owns the chemical reaction relationship with $A$ and $B$. If there is no the agency species between them, the value of the source relative rigidity is 0 .

$\mathrm{KAB}=\mathrm{KAC} \times \mathrm{KCB}$
$\mathrm{KBA}=\mathrm{KBC} \times \mathrm{KCA}$

(2) Relative rigidity: Because one species would perhaps affect many other species, the relative rigidity is expressed as the sum of one species' source relative rigidity towards all other species in an industrial ecosystem. (In the process of sum, the source relative rigidity should be weighted according to the importance of every industrial chain. However in this paper, the weight is assumed equally.)

$K=\sum_{i=1} K_{i}$

where $K$ is relative rigidity, $K_{i}$ is source relative rigidity of one species to one other industrial species.

If there is one or several species with relative rigidity values that are substantially higher than the rest, that or those species would be defined as the dominant nodal point species. As a result, the dominant nodal point species can be classified into first dominant nodal point species, second dominant nodal point species, and so on, according to the values of relative rigidity. The dominant nodal point species have the most influence in the balance of input and output of other species in the industrial ecosystem.

2.3.2.6. System rigidity. The system stability is defined as the ability of one system recovering from the original deviation state to the balance state. System rigidity can be used to assess the contributions of one industrial species to the stability of whole industrial ecosystem. It can be calculated from the source relative rigidity of one species to the dominant nodal point species and its own absolute rigidity. The calculation methods of system rigidity of species are as follows:

$G_{s}=K_{i} \times G$

where $G_{s}$ is the system rigidity of species, $K_{i}$ is the source relative rigidity of one species to the dominant nodal point, and $G$ is the absolute rigidity of the species. 


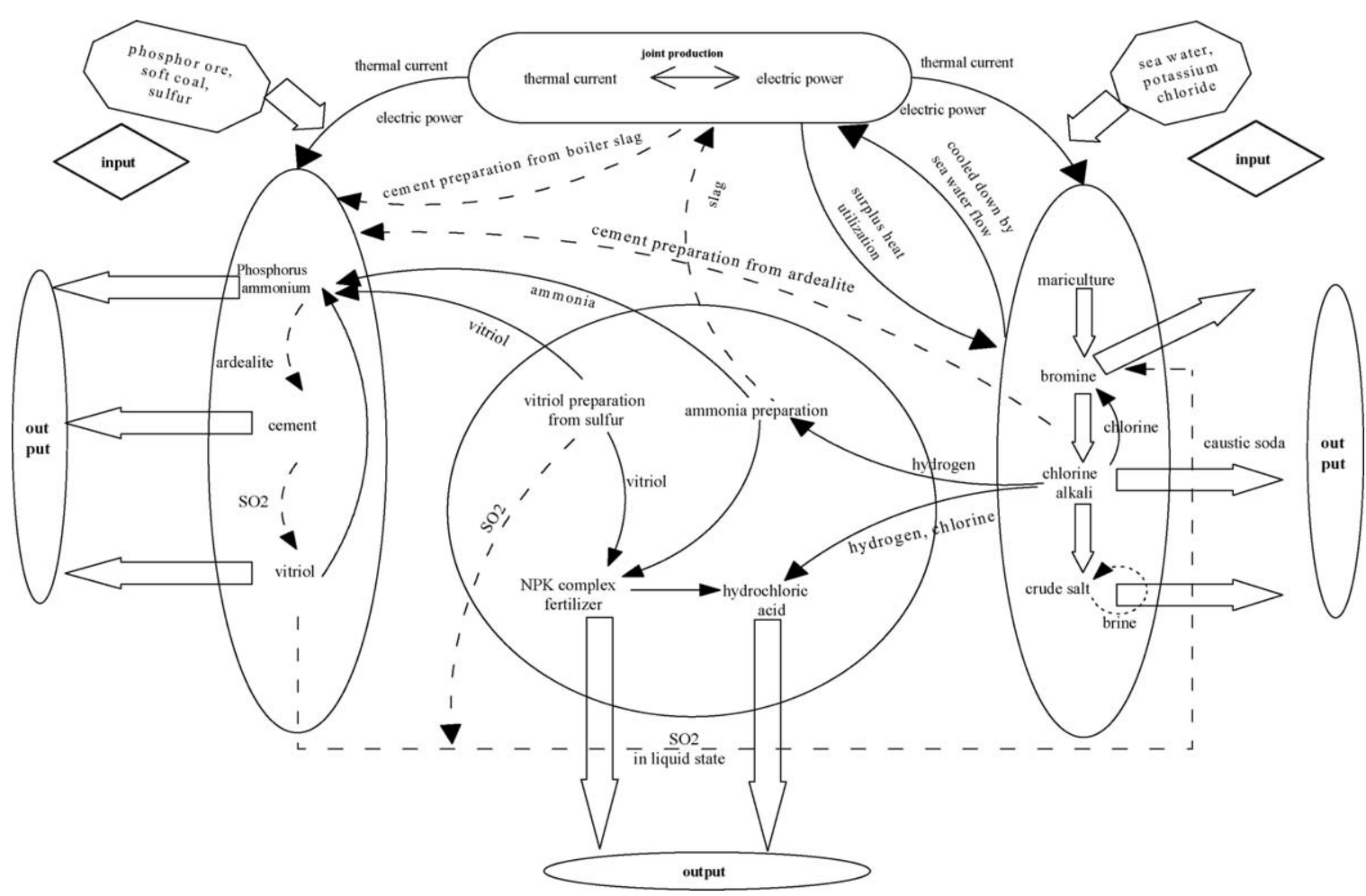

Fig. 1. The structure of LuBei industrial ecosystem.

A higher value of system rigidity indicates that the production chains associated with this species and the dominant nodal point species are more unstable in the industrial ecosystem. Conversely, a lower value entails that the production chains are more stable and are difficult to be destructed.

\section{LuBei industrial ecosystem}

LuBei Chemical Enterprise Group locates in Shan Dong province in China. In recent decade development, LuBei Chemical Enterprise improved some original production chains and added some advanced production chains in order to increase the production efficiency much more by circulating the waste in the industrial system. In 2003, the SEPA of China granted LuBei Chemical Enterprise Group as the Ecological Industrial Park.

\subsection{The structure of LuBei industrial ecosystem}

LuBei industrial ecosystem is composed of one horizontal industrial chain and two vertical industrial chains. The structure is described in Fig. 1.

The above 3 key industrial chains are the co-production chains of phosphorus ammonium, vitriol and cement; sea water chains; and the co-production chains of salt, alkali and electricity. These 3 chains constitute 4 categories of flows in the system, i.e., the materials flow, energy flow, wastes recycling flow and sea water flow. Some important products that link different industrial chains include Nitrogen Phosphorus Kalium complex fertilizer (NPK complex fertilizer), ammonia and hydrochloric acid, etc.

(1) Energy flow includes the co-generation of heat and electricity; the sea water cooling; and the surplus heat utilization and so on.

(2) Wastes recycling flow includes the processes of the abstraction of bromine from sea water by sulfur dioxide; the co-production of vitriol and cement by ardealite, salt gypsum and coal slag.
(3) Materials flow includes the utilization processes of vitriol, ammonia and chlorine.

(4) Sea water flow includes all processes of sea water chains.

\subsection{The main objects of analysis}

According to the present industrial production chains and the linkage intensity in LuBei industrial ecosystem, the 4 key production sub-chains are selected as the main objects of analysis. Those include the co-production of phosphorus ammonium, vitriol and cement (PSC), NPK complex fertilizer chains (S-NPK), the ammonia synthesis chains and the sea water chains.

\section{The results}

The original data used by this paper are provided by LuBei Chemical Enterprise Group in ShanDong province. Due to the original data are confidential, only the results would be analyzed and discussed in detail.

\subsection{The structure of the industrial ecosystem}

The species in LuBei industrial ecosystem are classified as the follows (Fig. 2):

Basal species: Sulfur, phosphor ore, potassium chloride, blind coal and sea water.

Intermediate species: Vitriol, sulfur dioxide, gypsum, phosphoric acid, ammonia, hydrogen and chlorine.

Top species: NPK complex fertilizer, cement, phosphorus ammonium, hydrochloric acid, bromine and caustic soda.

(1) IBSI $=1.3993, \quad$ ITSI $=0.856$. Only these two indices do not provide us enough information for the evaluation of industrial ecosystem. However, understanding of these two indices is helpful in two aspects. Firstly, it helps the decision makers to know whether the efficiency of the production could be 


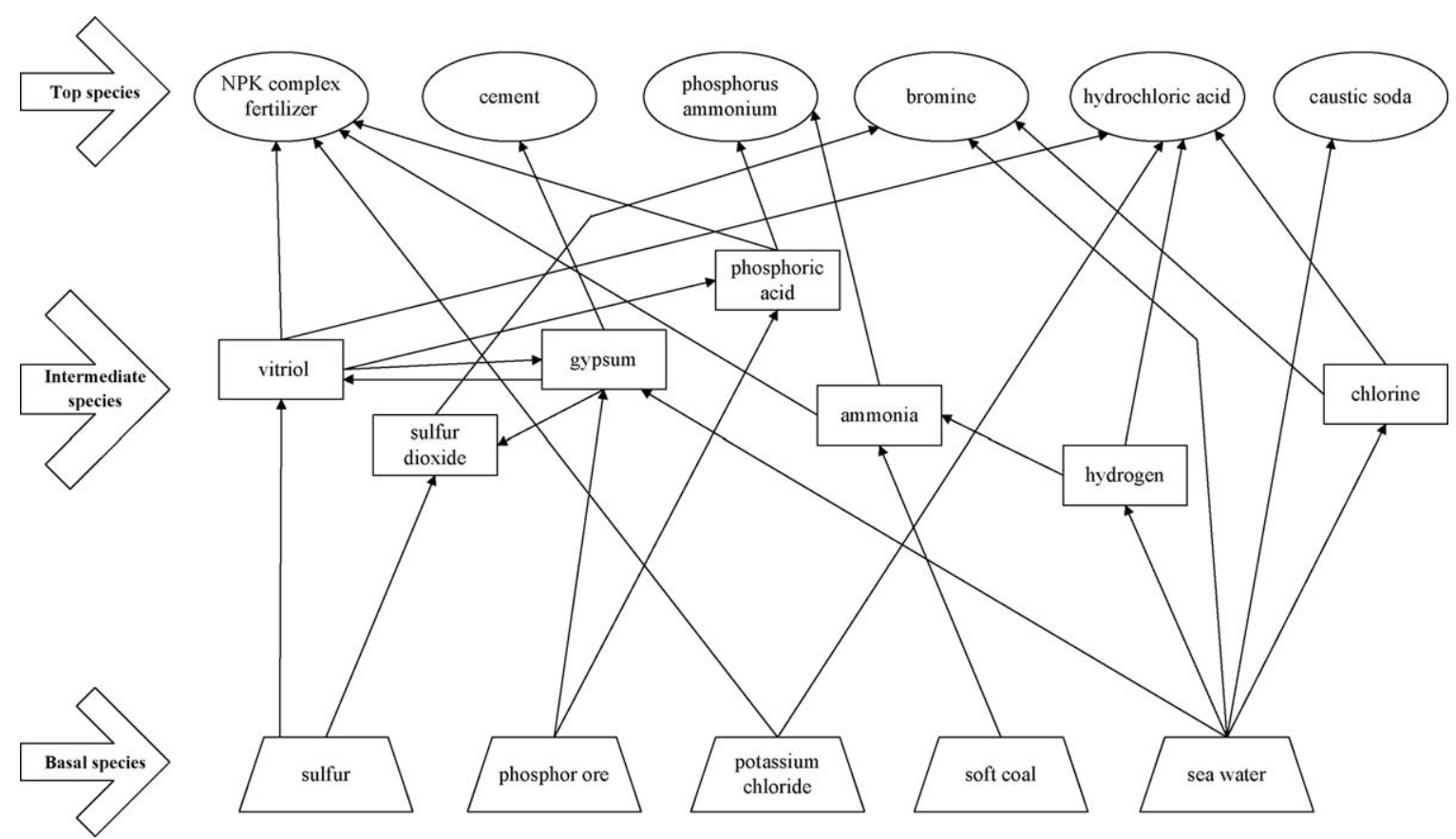

Fig. 2. The relationships of species in LuBei industrial ecosystem.

improved by restructuring of the production chains and the technology innovation. Secondly, it provides the comparison analysis of the production efficiency of the LuBei enterprise with other enterprises with the similar productions chains and technology.

(2) In the Fig. 2, PSC and S-NPK chains are shown on the left, ammonia synthesis chains are shown on the middle, while the sea water chains are shown on the right. It's apparent that the correlation among the industrial species on the left is denser than that on the right. So in LuBei industrial ecosystem, the relationships between raw materials and products in the sea water chains should be enhanced.

\subsection{The absolute rigidity of intermediate species}

The results of the absolute rigidity of the intermediate species in LuBei industrial ecosystem are shown in Table 3.

The absolute rigidity of hydrogen and sulfur dioxide are higher than others, indicating that the diversity of their sources and sinks should be strengthened in the system. In other words, the production ability of hydrogen and sulfur dioxide should be enhanced on the basis of feasible economic and technological conditions.

\subsection{The relative rigidity of the intermediate species}

The results of the relative rigidity of the intermediate species in LuBei industrial ecosystem are shown in Table 4.

Table 3

Absolute rigidity of intermediate species.

\begin{tabular}{llll}
\hline Intermediate species & Input rigidity & Output rigidity & $\begin{array}{l}\text { Absolute } \\
\text { rigidity }\end{array}$ \\
\hline Sulfur dioxide & 0.5200 & 1.0000 & 0.5200 \\
Vitriol & 0.5000 & 0.5000 & 0.2500 \\
Gypsum & 0.4800 & 1.0000 & 0.4800 \\
Chlorine & 1.0000 & 0.4100 & 0.4100 \\
Hydrogen & 0.8700 & 0.9700 & 0.8439 \\
Ammonia & 0.8000 & 0.5400 & 0.4320 \\
Phosphoric acid & 0.5600 & 0.5600 & 0.3136 \\
\hline
\end{tabular}

The relative rigidity of gypsum, vitriol and ammonia are higher than other species. So gypsum, vitriol and ammonia are regarded as the first, second and third dominant nodal points species respectively.

When the source relative rigidity of one intermediate species to another intermediate species or top species is calculated, only those species that have direct relationships should be considered. The value of source relative rigidity to other intermediate species or top species without direct relationships should be regarded as 0 .

\subsection{The system rigidity}

According to the source relative of every intermediate species to the first dominant nodal point species (Gypsum) and their own absolute rigidity, the system rigidity of intermediate species (Gs) in LuBei industrial ecosystem are calculated. The results are shown in Table 5.

The system rigidity of gypsum is the highest. This indicates that the production of gypsum mainly contribute to the balance of the input and output in the whole system. Therefore, gypsum is the key factor destructing the system stability and restraining the evolution of the system.

\section{Discussion}

The objectives of applying SAMIE to analyze an industrial ecosystem are to provide the decision makers with a reference to restructure the production chains and to innovate the technology. By the analysis results, the barriers of LuBei industrial ecosystem are accordant with the current practical situation in it. So the author thinks that the case study has proved that SAMIE is an effective tool to analyze the structural problems of industrial ecosystem in a new perspective.

(1) On the microscopic scale, the absolute rigidity of one species in an industrial ecosystem indicates the instability level of its own. So it's very necessary to enhance the diversity of sources and sinks of those species with high absolute rigidity in the industrial ecosystem. If the production chains cannot be 
Table 4

Relative rigidity of intermediate species.

\begin{tabular}{|c|c|c|c|c|c|c|c|}
\hline & \multicolumn{7}{|c|}{ Intermediate species } \\
\hline & Sulfur dioxide & Gypsum & Vitriol & Phosphoric acid & Ammonia & Hydrogen & Chlorine \\
\hline \multicolumn{8}{|l|}{ Top species } \\
\hline Cement & 0.0099 & 1.0000 & 1.0000 & 0.8889 & 0.8889 & 0.0357 & 0.0357 \\
\hline Phosphorus ammonium & 0.0129 & 0.5307 & 1.0000 & 1.0000 & 1.0000 & 0.0502 & 0.0502 \\
\hline Hydrochloric acid & 0.0907 & 0.4469 & 0.8421 & 0.4947 & 0.1263 & 0.1579 & 0.1579 \\
\hline NPK complex fertilizer & 0.0129 & 0.5307 & 1.0000 & 1.0000 & 1.0000 & 0.0502 & 0.0502 \\
\hline Caustic soda & 0.2547 & 0.4015 & 0.2547 & 0.2507 & 0.8000 & 1.0000 & 1.0000 \\
\hline Bromine & 1.0000 & 0.4015 & 1.0000 & 0.3844 & 0.8000 & 1.0000 & 1.0000 \\
\hline \multicolumn{8}{|l|}{ Intermediate species } \\
\hline Sulfur dioxide & 1.0000 & 0.6072 & 0.1852 & 0.0000 & 0.0000 & 0.0000 & 0.0000 \\
\hline Gypsum & 0.4387 & 1.0000 & 0.1021 & 0.7152 & 0.0000 & 0.1579 & 0.1579 \\
\hline Vitriol & 0.0129 & 0.5307 & 1.0000 & 0.6249 & 0.0000 & 0.0000 & 0.0000 \\
\hline Phosphoric & 0.0000 & 0.6491 & 0.1908 & 1.0000 & 0.0000 & 0.0000 & 0.0000 \\
\hline Ammonia & 0.0000 & 0.0000 & 0.0000 & 0.0000 & 1.0000 & 1.0000 & 0.0000 \\
\hline Hydrogen & 0.0000 & 1.0000 & 0.0000 & 0.0000 & 0.8000 & 1.0000 & 1.0000 \\
\hline Chlorine & 0.2547 & 0.2037 & 0.0000 & 0.0000 & 0.0000 & 1.0000 & 1.0000 \\
\hline Relative rigidity & 3.0874 & 7.3020 & 6.5739 & 6.3588 & 6.4152 & 5.4519 & 4.4519 \\
\hline
\end{tabular}

regulated appropriately in the short-term, the production of those species with high absolute rigidity should be enhanced and managed in other ways.

(2) On the medium scale, the relative rigidity of species in an industrial ecosystem (including source relative rigidity) indicates the contribution of this species to the instability of all other species' yield. Once the production of those species with high relative rigidity falls in trouble, the production of other species associated with them would perhaps be troubled too. Based on the relative rigidity, these highly unstable species could be managed in advance by technology innovation and efficiency improvement.

(3) On the macroscopic scale, the system rigidity of one species in an industrial ecosystem indicates the contribution of this species to the instability of whole ecosystem. It is the species with the highest system rigidity that dominates the stable level of whole industrial ecosystem, because the system rigidity is a synthetic indicator under the consideration of the absolute rigidity and source relative rigidity to the dominant nodal point species. If it's possible, the diversity of sources and sinks of those species with higher system rigidity should be increased by regulating, adding and improving the associated production chains.

(4) SAMIE provides us a new classification method for the species in one industrial ecosystem. The species in the industrial ecosystem can be classified into 3 levels. The first level includes the species with highest system rigidity. The second level includes the species with highest relative rigidity. The third level includes the species with highest absolute rigidity. The most important species are on the first level. The species on the second level are less important than those on the first level. And the species on the third level are less important than those on the first and second level. Therefore, decision makers should pay much attention to those important species and the

Table 5

System rigidity of intermediate species.

\begin{tabular}{llll}
\hline $\begin{array}{l}\text { Intermediate } \\
\text { species }\end{array}$ & $\begin{array}{l}\text { Absolute } \\
\text { rigidity }(G)\end{array}$ & $\begin{array}{l}\text { Relative } \\
\text { rigidity }(K)\end{array}$ & $\begin{array}{l}\text { System } \\
\text { rigidity }\left(G_{S}\right)\end{array}$ \\
\hline Sulfur dioxide & 0.5200 & 0.4387 & 0.2281 \\
Vitriol & 0.2500 & 0.1021 & 0.0255 \\
Gypsum & 0.4800 & 1.0000 & 0.4800 \\
Chlorine & 0.4100 & 0.1579 & 0.0647 \\
Hydrogen & 0.8439 & 0.1579 & 0.1333 \\
Ammonia & 0.4320 & 0.0000 & 0.0000 \\
Phosphoric acid & 0.3136 & 0.7152 & 0.2243 \\
\hline
\end{tabular}

associated production chains. If an enterprise decides, for some reasons, to abandon or reduce the production of some species, the species in lower level or with lower importance and less economic value should be selected to ensure the highest productivity of the industrial ecosystem and the least negative effects on the industrial ecosystem.

(5) In the case study on LuBei, the Species Index (including IBSI and ITSI) is calculated. IBSI indicates the efficiency of raw material utilization; ITSI indicates the efficiency of wastes recycling. These two indices are designed in SAMIE in order to evaluate the eco efficiency in the industrial ecosystem. But perhaps only these two indices cannot reflect all the vision of the eco efficiency in one industrial ecosystem. So the indicator system of SAMIE should be improved more comprehensive in the future.

\section{Conclusions}

(1) According to the SAMIE approach, LuBei Chemical Enterprise Group has established the embryonic structure and functions of its industrial ecosystem. Three main industrial chains have been selected as the frame including the co-production of phosphorus ammonium, vitriol and cement; sea water chains; and the co-production of salt, alkali and electricity. Such chains as NPK complex fertilizer, ammonia synthesis, etc. have been used as the channels. Energy cascade utilization including thermal power and electricity has been taken as the nutrient and blood.

(2) Based on the SAMIE approach, the raw materials, wastes and products in LuBei industrial ecosystem are analogously classified and defined as basal species, intermediate species and top species. The Definitions and calculation methods for absolute rigidity, relative rigidity, system rigidity, IBSI and ITSI have been explained in detail.

(3) In LuBei industrial ecosystem, IBSI $=1.3993$, ITSI $=0.856$. The absolute rigidity of hydrogen (0.8439) and sulfur dioxide $(0.5200)$ are the highest among the species. Gypsum (7.302), vitriol (6.5739), and ammonia (6.4152) have the highest relative rigidity. The species with the highest system rigidity is Gypsum (0.4800).

\section{Acknowledgements}

This paper was supported by the "National Basic Research (973) Program" Project (No. 2005CB724206) of the Ministry of Science and Technology of China. Dr. Zhanfeng. Liu of Research Center for 
Eco-Environmental Sciences, Chinese Academy of Sciences, and Mr. Kuo Wang of the University of Massachusetts provided great help in revising this paper.

\section{References}

Adriaansee, A., Bringzu, S., Hammond, A., Morigutchi, Y., Rodenburg, E., Rogich, D., 1997. Resource Flows: The Material Basis of Industrial Economies. World Resources Institute, Washington, DC.

Anderberg, S., 1998. Industrial metabolism and the linkages between economics, ethics and the environment. Ecological Economics 24, 311-320.

Andrews, C.J., 2001. Building a micro foundation for industrial ecology. Journal of Industrial Ecology 4 (3), 35-51.

Ayres, R.U., 1989. Industrial metabolism. In: Ausubel, J., Sladovich, H. (Eds.), Technology and Environment. National Academy Press, Washington, DC, pp. 23-49.

Ayres, R.U., Simonis, U.E. (Eds.), 1994. Industrial Metabolism: Restructuring for Sustainable Development. United Nations University Press, Tokyo.

Ayres, R.U., Schlesinger, W.H., Socolow, R.H., 1994. Human impacts on the carbon and nitrogen cycles. In: Socolow, R.H., Andrews, C.J., Berkhout, F., Thomas, V.M (Eds.), Industrial Ecology and Global Change. Cambridge University Press, Cambridge, pp. 121-155.

Azovsky, Andrey, I., 2009. Structural complexity of species assemblages and spatial scale of community organization: a case study of marine benthos. Ecologica Complexity 6, 308-315.

Baccini, P., Brunner, P.H. (Eds.), 1991. Metabolism of the Anthroposphere. Springer-Verlag, Berlin.

Bringezu, S., 2000. History and overview of material flow analysis. In: Paper Presented to the OECD Special Session on Material Flow Accounting, 30th Meeting of the Working Group on the State of the Environment, Organization for Economic Cooperation and Development, Paris, October.

Bringezu, S., Fischer-Kowalski, M., Kleijn, R., Palm, V., 1997. Analysis for action: support for policy towards sustainability by material flow accounting. In: Wuppertal (Eds.), Wuppertal Special 6. Wuppertal Institute, Germany.

Brown, M.T., Herendeen, R.A., 1996. Embodied energy analysis and emergy analysis: a comparative view. Ecological Economics 19, 219-235.

Cadenasso, M.L., Pickett, S.T.A., Grove, J.M., 2006. Dimensions of ecosystem complexity: heterogeneity, connectivity, and history. Ecological Complexity 3, 1-12.

Cohen-Rosenthal, E., 2004. Making sense out of industrial ecology: a framework for analysis and action. Journal of Cleaner Production 12, 1111-1123.

Cote, R.P., Cohen-Rosenthal, E., 1998. Designing eco industrial park: a synthesis of some experiences. Journal of Cleaner Production 6 (3/4), 181-198.

Daniels, P.L., Moore, S., 2002. Approaches for quantifying the metabolism of physical economies. Journal of Industrial Ecology 5 (4), 69-93.

Finnveden, G., Moberg, A., 2005. Environmental systems analysis tools-overview. Journal of Cleaner Production 13, 1165-1173.

Frosch, R.A., Gallopoulos, N.E., 1989. Strategies for manufacturing. Scientific American 261 (September), 144-152.

Gleser, L.J., 1997. Some thoughts on chemical mass balance models. Chemometrics and Intelligent Laboratory Systems 37, 15-22.

Graedel, T.E., 1994. Industrial ecology: definition and implementation. In: Socolow, R.H., Andrews, C.J., Berkhout, F., Thomas, V.M. (Eds.), Industrial Ecology and Global Change. Cambridge University Press, Cambridge, pp. 23-41.

Graedel, T.E., Allenby, B.R.(Eds.), 1995. Industrial Ecology. Prentice Hall, Eaglewood Cliffe, NJ.

Guinee, J.B., Van den Bergh, J.C.J.M., Boelens, J., Fraanje, P.J., Huppes, G., Kandelaars, P.P.A.A.H., Lexmond, Th.M., Moolenaar, S.W., Olsthoorn, A.A., Udo de Haes, H.A., Verkuijlen, E., van der Voet, E., 1999. Evaluation of risks of metal flows and accumulation in economy and environment. Ecological Economics 30, 47-65.

Harper, E.M., Graedel, T.E., 2004. Industrial ecology: a teenager's progress. Technology in Society 26, 433-445.

ISO, 1997. Environmental Management - Life Cycle Assessment - Principles and Framework. International Organization for Standardization, International Standard ISO 14040.

ISO, 1998. Environmental Management - Life Cycle Assessment - Goal and Scope Definition and Inventory Analysis. International Organization for Standardization, International Standard ISO 14041.
ISO, 1999. Environmental Management - Life Cycle Assessment - Life Cycle Impact Assessment. International Organization for Standardization, International Standard ISO 14042

Joshi, S., 2000. Product environmental life-cycle assessment using input-output techniques. Journal of Industrial Ecology 3 (2/3), 95-120.

Korhonen, J., 2002. Two paths to industrial ecology: applying the product-based and geographical approaches. Journal of Environmental Planning and Management 45 (1), 39-57.

Krebs, C.J. (Ed.), 2001. Ecology: The Experimental Analysis of Distribution and Abundance. fifth ed. Cummings, Benjamin

Lave, L.B., Cobas- Flores, E., Hendrickson, C.T., McMichael, F.C., 1995. Using inputoutput analysis to estimate economy-wide discharges. Environmental Science and Technology 29 (9), 420A-426A.

Li, B.L., 2004. Editorial. Ecological Complexity 1, 1-2.

Matthews, E., Amann, C., Bringezu, S., Fischer-Kowalski, M., Huttler, W., Kleijn, R., Moriguchi, Y., Ottke, C., Rodenburg, E., Rogich, D., Schandl, H., Schutz, H., van der Voet, E., Weisz, H., 2000. The Weight of Nations: Material Outflows from Industrial Economies. World Resources Institute, Washington, DC.

Miller, R.E., Blair, P.D. (Eds.), 1985. Input-Output Analysis: Foundations and Extensions. Prentice-Hall, Inc., Englewood Cliffs, New Jersey.

Odum, H.T., 1988. Self-organization, transformity and information. Science 242, $1132-1139$.

Odum, H.T., 1994. The emergy of natural capital. In: Jansson, A.M., Folke, C., Costanza, R. (Eds.), Investing in Natural Capital. Island Press, Covelo, CA, pp. 200212

Odum, H.T. (Ed.), 1996. Environmental Accounting: Emergy and Environmental Decision-Making. Wiley, New York.

Onaindia, M., Dominguez, I., Albizu, I., Garbisu, C., Amezaga, I., 2004. Vegetation diversity and vertical structure as indicators of forest disturbance. Forest Ecology and Management 195, 341-354.

O’Rourke, D., Connelly, L., Koshland, C.P., 1996. Industrial ecology: a critical review. International Journal of Environment and Pollution 6 (2/3), 89-112.

Pederson, O.G. (Ed.), 1998. Physical Input-Output Tables for Denmark. Statistics Denmark, Copenhagen.

Ratze, Cedric, Gillet, Francois, Muller, Jean-Pierre, Stoffel, Kilian, 2007. Simulation modeling of ecological hierarchies in constructive dynamical systems. Ecological Complexity 4, 13-25.

Simpson, E.H., 1949. Measurement of diversity. Nature 163, 688.

Spangenberg, J.H., Hinterberger, F., Moll, S., Schutz, H., 1999. Material Flow Analysis TMR and the MIPS-Concept: A Contribution to the Development of Indicators for Measuring Changes in Consumption and Production Patterns. Wuppertal Institute for Environment, Climate and Energy, Department for Material Flows and Structural Change, Wuppertal.

Stahmer, C., Kuhn, M., Braun, N., 1997. Physical input-output tables for Germany, 1990. Report Prepared for DG XI and Eurostat. Eurostat Directorate B, Luxembourg.

Thomas, V.M., Spiro, T., 1994. Emissions and exposure to metals: cadmium and lead. In: Socolow, R.H., Andrews, C.J., Berkhout, F., Thomas, V.M. (Eds.), Industrial Ecology and Global Change. Cambridge University Press, Cambridge, pp. 297318.

Udo de Haes, H.A., Jolliet, O., Finnveden, G., Hauschild, M., Krewitt, W., MullerWenk, R., 1999. Best available practice regarding impact categories and category indicators in life cycle impact assessment, background document for the second working group on life cycle impact assessment of SETAC-Europe. Part 1 and 2. International Journal of Life Cycle Assessment 4, 66-74.

Udo de Haes, H.A., Finnveden, G., Goedkoop, M., Hauschild, M., Hertwich, E.G., Hofstetter, P., Jolliet, O., Klopffer, W., Krewitt, W., Lindeijer, E., Muller-Wenk, R., Olsen, S.I., Pennington, D.W., Potting, J., Steen, B. (Eds.), 2002. Life-Cycle Impact Assessment: Striving Towards Best Practice. SETAC Press, Pensacola, FL.

Ulanowicz, Robert, E., 2004. On the nature of ecodynamics. Ecological Complexity 1, $341-354$.

Ulgiati, S., Brown, M.T., 1998. Monitoring patterns of sustainability in natural and man-made ecosystems. Ecological Modelling 108, 23-36.

Vigon, B.W., Tolle, D.A., Cornaby, B.W., Latham, H.C. (Eds.), 1993. Life Cycle Assessment: Inventory Guidelines and Principles. EPA Press, Cincirunati, pp. 87-93.

Yang, P.P-J., Lay, O.B., 2004. Applying ecosystem concepts to the planning of industrial areas: a case study of Singapore's Jurong Island. Journal of Cleaner Production 12, 1011-1023. 